J. Hucińska, G. Gajowiec

Gdansk University of Technology, Mechanical Engineering Faculty, Gdansk, Poland

\title{
ASSESSMENT OF FITNESS FOR SERVICE OF Cr-Mo STEEL TUBES IN CATALYTIC REFORMING CHARGE HEATERS
}

\begin{abstract}
In this paper characteristic features of metal dusting corrosion in high temperature gas mixtures of high carbon activity in catalytic reforming units, including Continuous Catalyst Regeneration (CCR) platformer are presented. Examples of $2.25 \mathrm{Cr}-1 \mathrm{Mo}$ and $9 \mathrm{Cr}-1 \mathrm{Mo}$ steel tubes at advanced stages of metal dusting process after long-term service in charge heaters are used to prove that destructive examinations are necessary to provide certain information about possible mechanisms of damage, and are helpful in assessment of immediate fitness for purpose and long-term service capability of the components during and following shut-downs.
\end{abstract}

Key words: metal dusting, catalytic reformers, Cr-Mo steels, fitness for service

\section{INTRODUCTION}

Metal dusting is a high temperature corrosion phenomenon that involves disintegration of compact metallic materials into powder consisting of metal, carbon, carbides and oxides [1-3]. The corrosion occurs in gas mixtures of high carbon activities $\mathrm{a}_{\mathrm{C}}>1$, enriched in hydrogen, carbon oxide or hydrocarbons, mainly at temperatures between 400 and $700^{\circ} \mathrm{C}$. Metal dusting problems have been encountered in many processes in petrochemical, chemical, refinery and heat treatment industries. Alloys found to suffer metal dusting include carbon steels, chromium-molybdenum (Cr-Mo) steels, stainless steels and nickel-base alloys. The decomposition of the materials leads to uniform thinning or severe pitting that is associated with considerable safety risks.

Numerous works have been carried out to explain the mechanism and the kinetics of metal dusting process. The works of Grabke et al. are of particular importance [3-8]. The corrosion was simulated in flowing $\mathrm{CO}-\mathrm{H}_{2}-\mathrm{H}_{2} \mathrm{O}$ laboratory mixtures. It was shown that metal dusting corrosion of iron and low alloy Cr-Mo steels starts with the carbon over-saturation of near-surface regions that leads to formation of metastable cementite $\mathrm{Fe}_{3} \mathrm{C}$ layer at the metal surface. With the reaction progression, the carbide is destabilized by the carbon deposition and dissociates into carbon and iron particles. The experimental evidence for this metal dusting model relies on thermogravimetry and on examinations of the end products of the corrosion. Studies of the corrosion interface at the nano level using transmission electro microscope (TEM) carried out by Pippel et al. $[9,10]$ and Chun et al. [11,12] have significantly extended the micro-mechanistic aspects of metal dusting of iron and Cr-Mo steels. 
Recent studies on metal dusting of 9Cr-1Mo steel in hydrocarbons and hydrogen gas environment in refinery charge heaters have revealed that metal dusting corrosion may proceed in a different way than it could be expected from the laboratory experiments $[13,14]$. Moreover, a new metal dusting models were proposed supported by examinations of the after service material only, because other methods, like thermogravimetry or TEM investigations of thin foils after exposure under metal dusting conditions are impossible to be carried out in industrial installations.

In this paper samples of Cr-Mo steels subject to metal dusting in refinery charge heaters in catalytic reforming units, including CCR platformer are presented to show that characteristics of metal dusting process can be acquired from examinations of the end products of the corrosion, in great part using SEM technique. The aim of this work is to prove that these examinations can be helpful in an assessment of immediate fitness for the purpose and long-term service capability of the components.

\section{EXPERIMENTAL}

Commercial 2.25Cr-1Mo and 9Cr-1Mo steel tubes after ten years' service in refinery charge heaters were subjected to tests. The characteristics of the steel and the service conditions are shown in Table 1. It can be seen that both of the steel tubes operated under similar conditions. The inside surfaces (IS) of the tubes were in contact with hydrocarbons and hydrogen gas mixture passing inside, and their outside surfaces (OS) were heated by burners situated in the heater boxes.

Fragments of maximum OS/metal skin temperatures were cut out from the tubes and plane cross sections of the tube walls were prepared metallographically. A sample of $2.25 \mathrm{Cr}-1 \mathrm{Mo}$ steel was etched using a solution of $4 \%$ by volume of nitric acid in ethanol. For etching $9 \mathrm{Cr}-1 \mathrm{Mo}$ steel, a solution of $6 \mathrm{wt} . \%$ picric acid and $1 \%$ by volume of hydrochloric acid in ethanol was used. The samples were examined by means of a field emission Hitachi 4200 scanning electron microscope (SEM) and a Hitachi S$3400 \mathrm{~N}$ SEM, both linked with an X-ray energy dispersive spectrometer (EDS). The examinations were performed at accelerating voltage $25 \mathrm{kV}$. Correction system PROZA (Phi-Rho-Z) was used. Chemical composition of carbides in the steel layer situated beneath the IS of the tubes was under investigation. To assess the distribution of chromium and molybdenum across the cross-sections of the tube walls, the SEM/EDS analyses of an average chemical composition in areas of $10 \mu \mathrm{m} \times 100 \mu \mathrm{m}$, with the shorter edge perpendicular to the IS of the tubes were performed. Some areas beneath the IS and in the middle-wall material were under analyses.

Table 1. Characteristics of 2.25Cr-1Mo and 9Cr-1Mo steel tested and the service conditions

\begin{tabular}{lll}
\hline Characteristics & 2.25Cr-1Mo steel & 9Cr-1Mo steel \\
\hline Grade/size of tube & T22 ASTM SA-213, $\phi 114 \times 6 \mathrm{~mm}$ P9 ASTM SA-335 $\phi 114 \times 6 \mathrm{~mm}$ \\
Unit type & Catalytic reforming & CCR platforming \\
& Hydrotreated naphtha and & Hydrotreated naphtha and \\
Feed & hydrogen gas, sulphur content in & hydrogen gas, sulphur content in \\
& the naphtha $\sim 0.3 \mathrm{ppm}$, & the naphtha $\sim 0.3 \mathrm{ppm}$, \\
& temperature $520^{\circ} \mathrm{C} \max$. & temperature $520^{\circ} \mathrm{C}$ max. \\
Metal skin temp. & $600^{\circ} \mathrm{C} \mathrm{max}$ & $600^{\circ} \mathrm{C} \max$.
\end{tabular}




\section{CORROSION PRODUCTS AND SUBSURFACE ZONE EXAMINATIONS}

\section{Characteristics of $2.25 \mathrm{Cr}-1 \mathrm{Mo}$ steel}

Fig. 1(a) presents a SEM micrograph of the cross section of 2.25Cr-1Mo steel sample close to the IS of the tube. The surface is rough and covered with dark compact corrosion products (1). Beneath the surface, big spheroidal and elongated carbide particles (2), uniformly distributed in the metal matrix are present. Some of the particles are linked together. Just at the surface, the carbides are so closely distributed that they form a thin not uniform layer (3). The layer reaches a thickness of about $2 \mu \mathrm{m}$ and is ruptured in some places. At higher magnification of Fig. 1(b) some discontinuities between the layer and the underlying material can clearly be seen. It is possible to conclude that metal losses seem likely to form by separation of fragments of the subsurface layer from the substrate. The SEM/EDS analyses have revealed that the carbides within the layer and in the underlying material contain about 2-4 wt.\% of chromium, 1-2 wt.\% of molybdenum and $0-4 \mathrm{wt} . \%$ of silicon. The rest is iron. Some results of the examinations and the errors are shown in Fig. 2(a), (b).

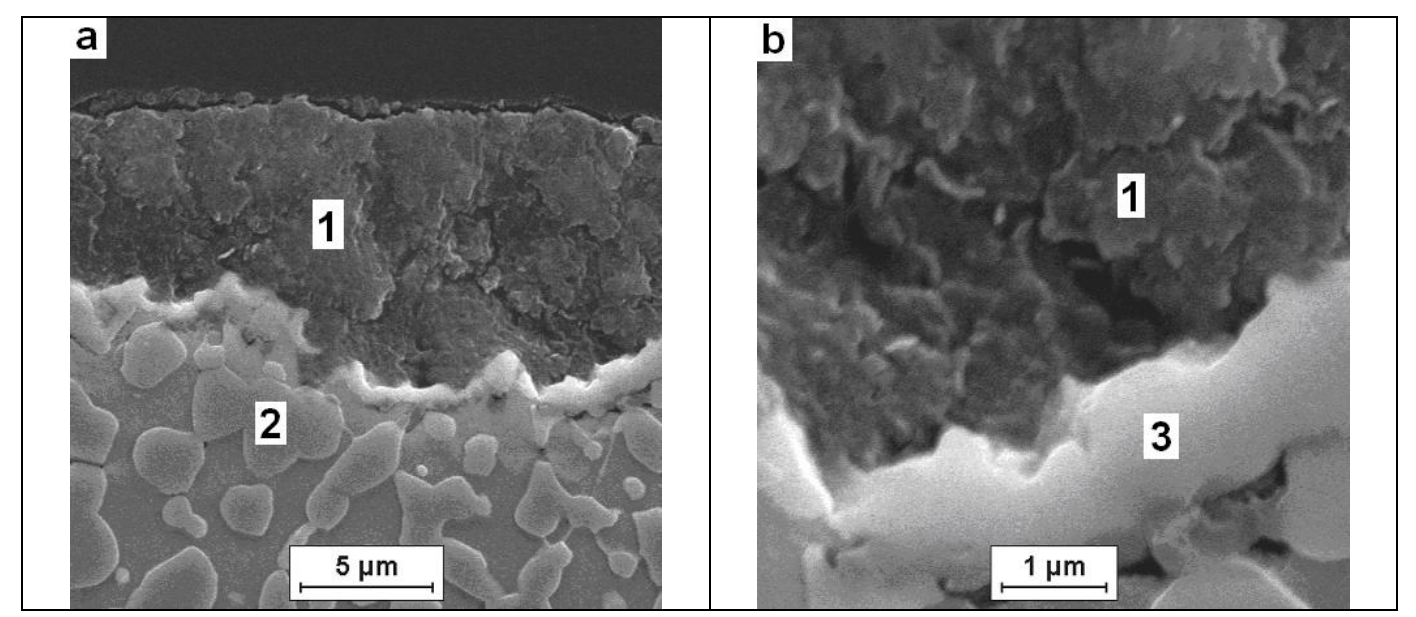

Fig. 1(a), (b). Micrographs of the cross-section of 2.25Cr-1Mo steel tube wall close to the IS: 1 - corrosion products, 2 - big carbides in the metal matrix, 3 - a carbide layer at the surface

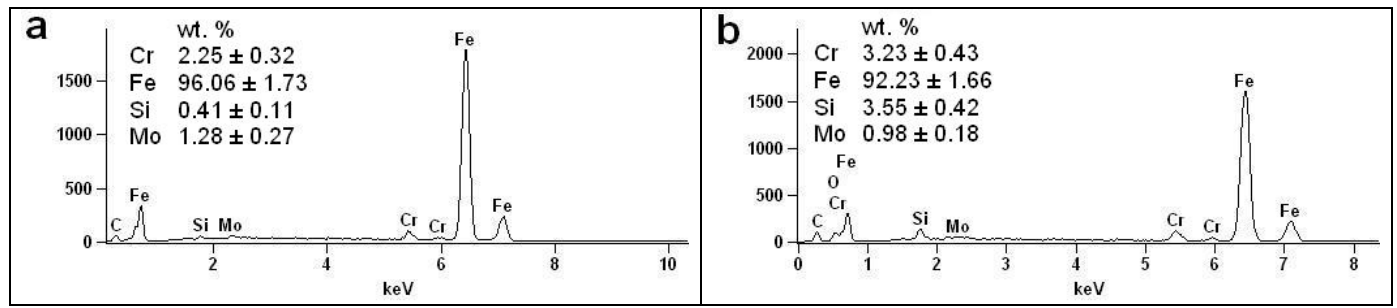

Fig. 2(a), (b). Results of SEM/EDS analyses of carbides in $2.25 \mathrm{Cr}-1 \mathrm{Mo}$ steel: (a) at point 2 indicated in Fig. 1(a), (b) at point 3 in Fig. 1(b)

\section{Characteristics of 9Cr-1Mo steel}

In Fig. 3 a SEM micrograph of the cross section of 9Cr-1Mo steel sample close to the IS of the tube is shown. It can be noted that the steel surface is rough, covered with fragile 
and porous corrosion products, and many fine pits and fissures develop in the subsurface zone of the steel.

Detailed SEM examinations have revealed a complex microstructure of the subsurface steel zone. According to a micrograph in Fig. 4(a), a thin layer of about $2 \mu \mathrm{m}$ in thickness composed of fine precipitates (1) exists just beneath the surface. There is about 50-55 wt.\% of chromium and 0-4 wt.\% of silicon in the layer on the average. The rest is iron. The layer is followed by a not-coherent zone containing big degraded primary carbides (2), i.e. the carbides that were present in the steel before service and underwent some unavoidable transformations. The carbides are situated in a 'matrix' composed of fine globular carbides (3), instead of alloy ferrite. The amount of the alloy elements, i.e. chromium and molybdenum in the precipitates is differentiated. Bigger primary carbides contain about 20-25 wt. $\%$ of chromium and 2-4 wt. $\%$ of molybdenum. The fine carbides which form the 'matrix' contain less of the alloy elements than the bigger primary carbides. However, the concentration of chromium and molybdenum in the 'matrix' is higher than in the alloy ferrite before service: about $14-18 \mathrm{wt} . \%$ and 1-3 wt.\% in comparison with about 9 and $1 \mathrm{wt} . \%$. Some results of the analyses are shown in Fig. 4(b). Because of the material porosity and small dimensions of the precipitates, the results refer to groups of the particles and have a comparative meaning.

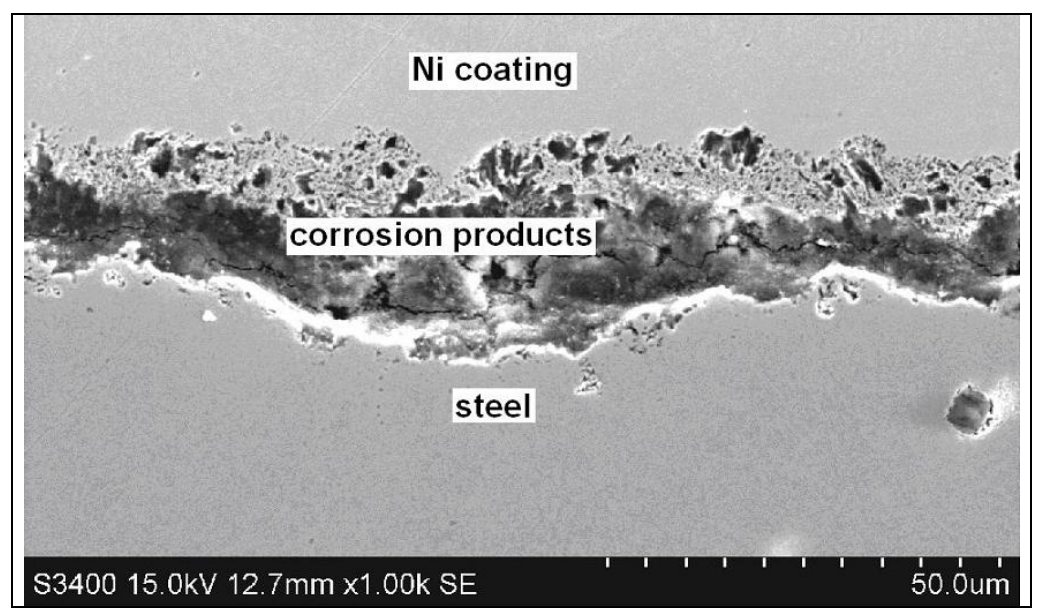

Fig. 3. Corrosion products on the IS of $9 \mathrm{Cr}-1 \mathrm{Mo}$ steel tube and a porous steel zone beneath the surface 


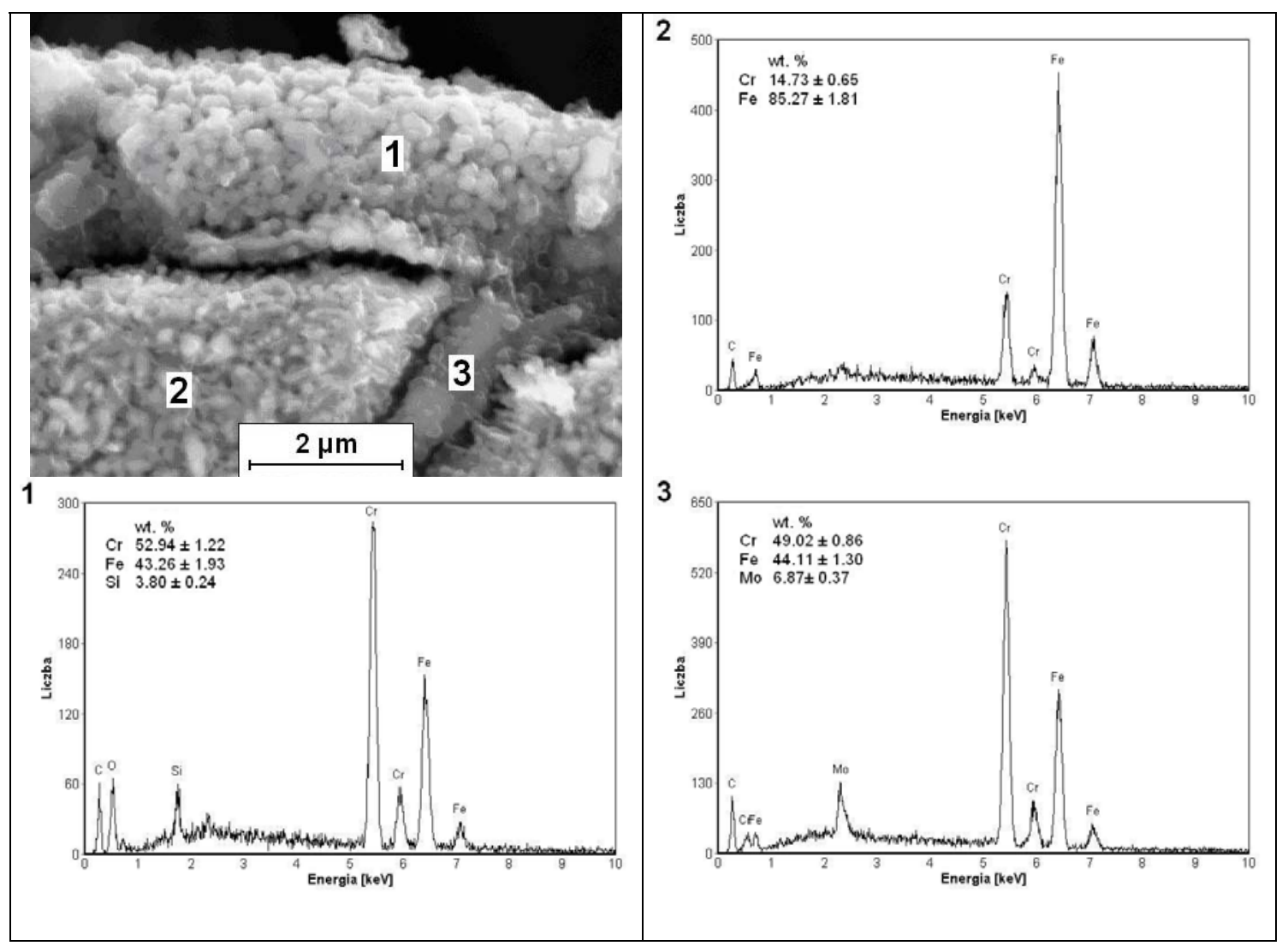

Fig. 4. A micrograph of the cross-section of $9 \mathrm{Cr}-1 \mathrm{Mo}$ steel tube wall close to the IS and results of SEM/EDS analyses: 1 - a layer of fine carbides at the steel surface, 2 - a 'matrix' composed of fine carbides, 3 - degraded primary carbide

\section{MICROSTRUCTURE ACROSS THE TUBE WALL}

\section{Characteristics of 2.25Cr-1Mo steel}

Figs. 5(a) through (f) illustrate the microstructure across 2.25Cr-1Mo steel tube wall, starting from the IS and down to the middle-wall situated at a depth of $3 \mathrm{~mm}$. It can be seen that the morphology of carbides on the section is diversified: Fig. 5(a) indicates that beneath the IS, big spheroidal and elongated particles of diameter/length up to about $5 \mu \mathrm{m}$ prevail. The particles are quite uniformly distributed in the metal matrix covering about $50 \%$ of the area. Much smaller particles are present at a distance of 150.m $\mu$ from the IS in Fig. 5(b). However, they also cover about $50 \%$ of the area and their distribution in the matrix is rather uniform. Some thin, plate-like particles can also be noted. As illustrated in Figs. 5(c) through (e), the fraction of the carbides gradually decreases towards the middle-wall, the distribution of the particles in the matrix becomes not uniform, the carbides become smaller, and the fraction of the plate-like precipitates increases. In the middle-wall, fine carbides of not uniform distribution in the matrix dominate, Fig. 5(f). 


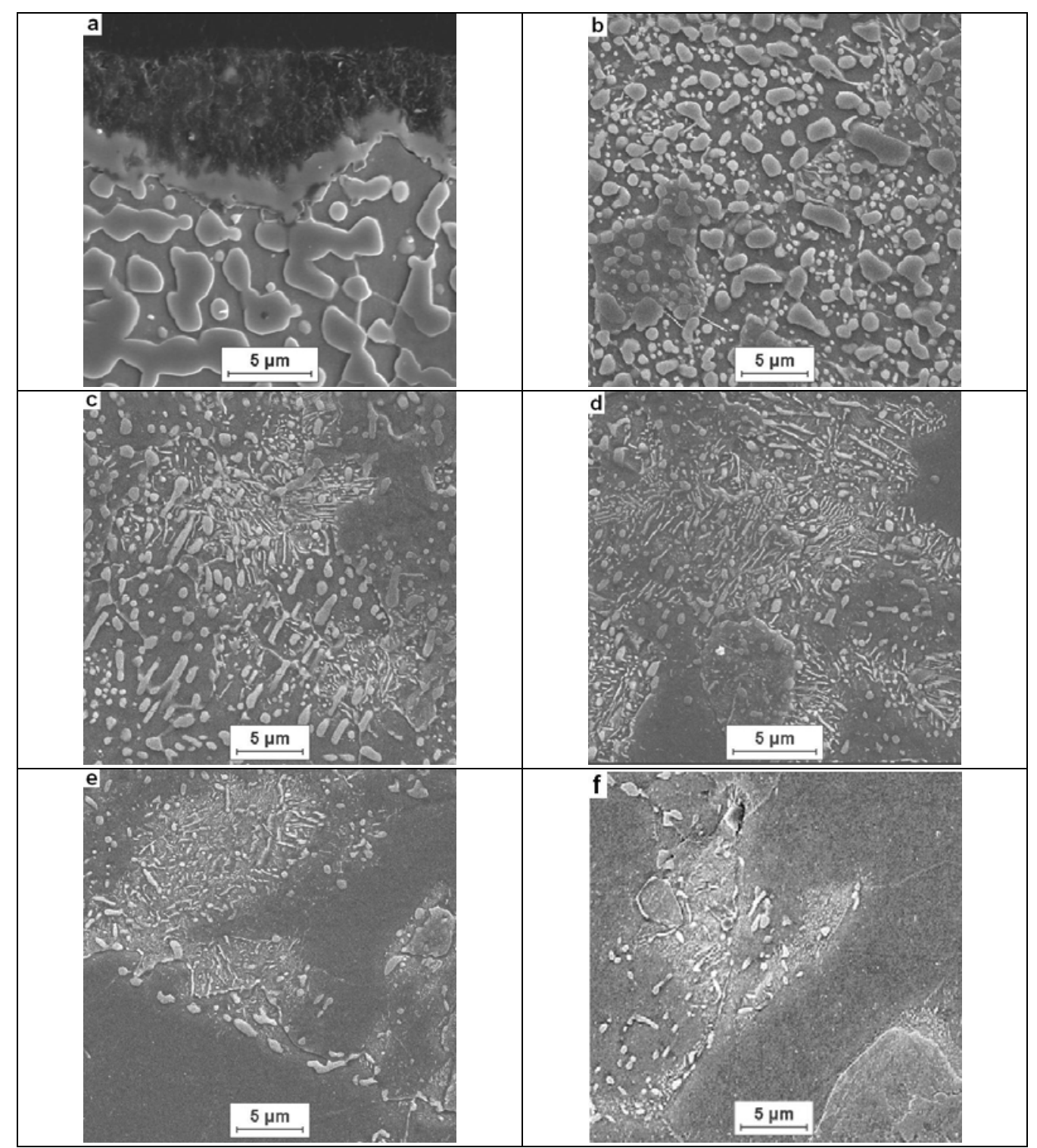

Fig. 5(a)-(f). Micrographs of the cross-section of 2.25Cr-1Mo steel tube wall: (a) the IS, (b)-(f) $150 \mu \mathrm{m}, 500$ $\mu \mathrm{m}, 750 \mu \mathrm{m}, 1 \mathrm{~mm}, 3 \mathrm{~mm}$ from the IS

\section{Characteristics of 9Cr-1Mo steel}

The microstructure features across $9 \mathrm{Cr}-1 \mathrm{Mo}$ steel tube wall are presented in Figs. 6(a) through (f). Like the zone situated close to the IS, which is shown in Fig. 4, the material situated at about $50 \mu \mathrm{m}$ from the surface is composed of big degraded primary carbides surrounded by a 'matrix' comprising carbide precipitates instead of alloy ferrite. The microstructure of this zone is shown in Fig. 6(a), (b). According to a micrograph in Fig. $6(\mathrm{c}),(\mathrm{d})$, some areas of the ferrite matrix with a dense network of fine carbides may be seen at about $200 \mu \mathrm{m}$ from the surface. At a depth of $700 \mu \mathrm{m}$, the ferrite grains and fine carbides mainly occurring at grain boundaries are illustrated in Fig. 6(e). The microstructure in this area is the same as the microstructure of the middle-wall material situated at a depth of $3 \mathrm{~mm}$, Fig. 6(f). 


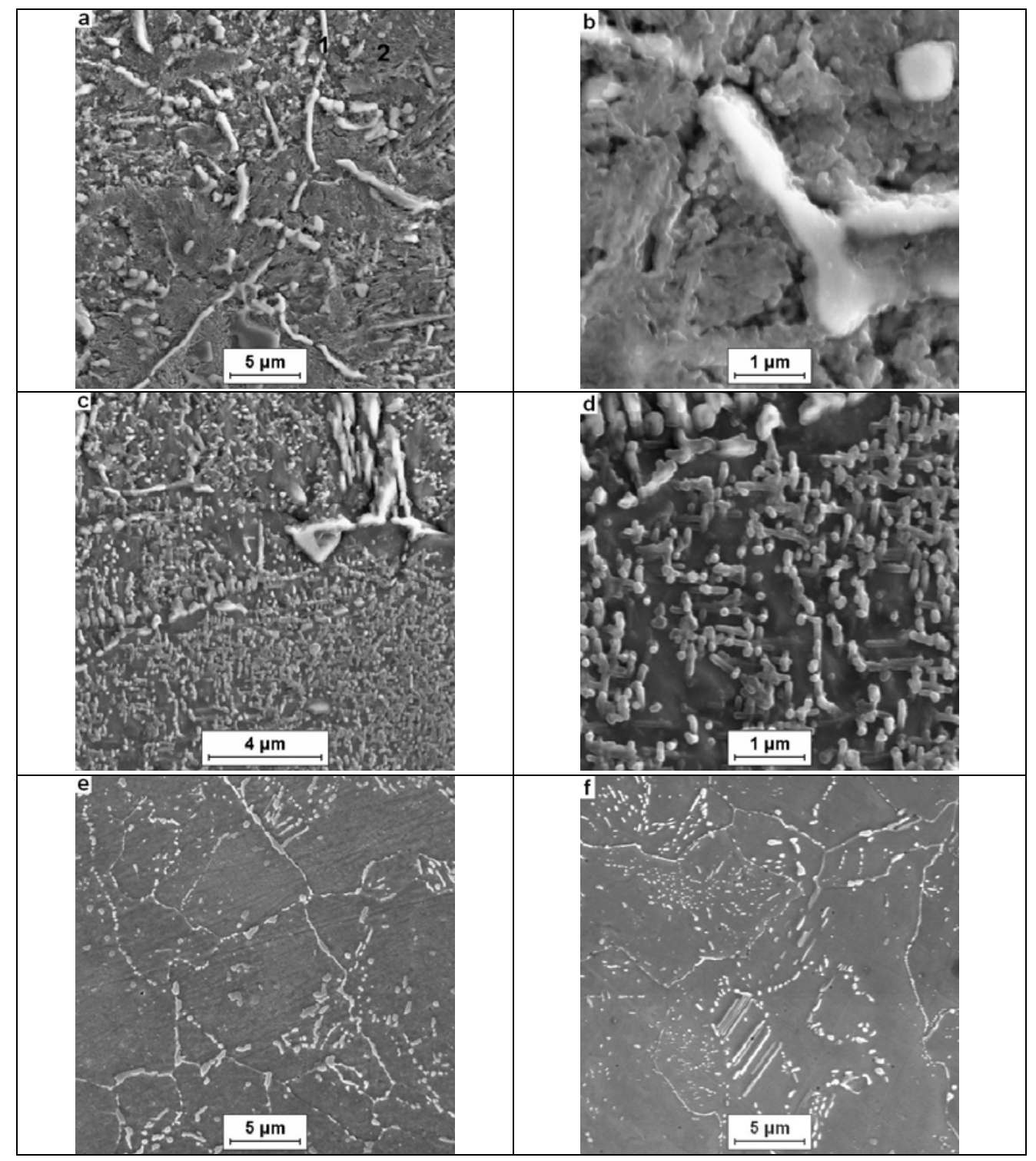

Fig. 6 (a)-(f). Micrographs of the cross-section of 9Cr-1Mo steel tube wall. Distances from the IS: (a),(b) 50 $\mu \mathrm{m}$, (c),(d) $200 \mu \mathrm{m}$, (e) $700 \mu \mathrm{m}$, (f) $3 \mathrm{~mm}$

\section{PROFILES OF CHROMIUM}

It is shown in Fig. 7 that chromium content beneath the surface of 9Cr-1Mo steel is higher than in the middle-wall, where about $9 \mathrm{wt} \% \mathrm{Cr}$ is noted. A maximum concentration of about $19 \mathrm{wt} . \%$ is reached at a distance of about $20 \mu \mathrm{m}$ from the steel surface. In $2.25 \mathrm{Cr}-1 \mathrm{Mo}$ steel tube however, the chromium content across the wall section is uniform. Because of low concentration of molybdenum in the steels, the profiles of this element are not presented. Of course, some enrichment of the subsurface areas of $9 \mathrm{Cr}-1 \mathrm{Mo}$ steel was recorded up to about $2 \mathrm{wt} . \%$. 


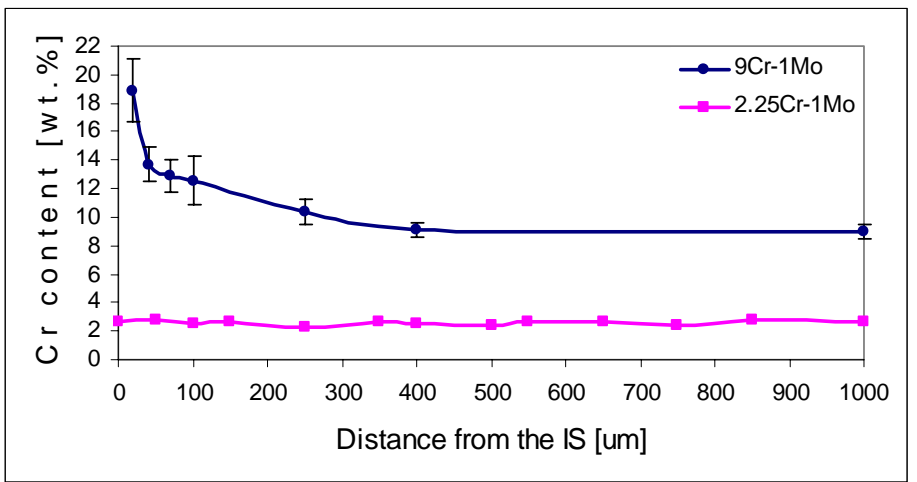

Fig. 7. Profiles of chromium from SEM/EDS analyses in areas of $10 \mu \mathrm{m} \times 100 \mu \mathrm{m}$

\section{DISCUSSION}

Metal dusting corrosion is one of the less known degradation mechanisms which lead to premature failure of equipment made of iron- and nickel-base alloys used in petrochemical, chemical, refinery and heat treatment industries. Numerous attempts have been made to understand the corrosion, and the mechanisms of the metal dusting process, including damage to Cr-Mo steels [3-13].

The presence of a well-developed inspection system of material degradation is a fundamental need for safety maintenance of any industrial installation. In hightemperature or high-pressure service, only shutdowns provide an opportunity to collect up-to-date data on equipment condition. Metal dusting can be indicated through component thinning higher than expected, using conventional non-destructive methods. However, an ideal step would be to sample a worst-case component and to assess the mechanism and the extent of the corrosion across the component section by metallography.

In this paper samples collected from $2.25 \mathrm{Cr}-1 \mathrm{Mo}$ and $9 \mathrm{Cr}-1 \mathrm{Mo}$ steel tubes that were under metal dusting conditions at about $600^{\circ} \mathrm{C}$ for 10 years in catalytic reforming charge heaters are presented to prove that the SEM/EDS technique can quickly provide information about the state of corrosion products, the chemistry and the microstructure of the subsurface zone attacked by carbon, the extent of carbon transport and the changes in the chemical composition across the component section. It should be noted however, that the SEM/EDS analyses of carbides in the steels are of qualitative meaning only, because of the material porosity, dense distribution of the carbides and small dimensions of some particles. The results of the examinations indicate, that the inward transport of carbon into the steels up to over-saturation of the materials beneath the IS has taken place as evidenced by formation of multiples carbide precipitates. In $9 \mathrm{Cr}-1 \mathrm{Mo}$ steel the transport of carbon is accompanied by the outward diffusion of chromium and molybdenum which are stronger carbide-formers than iron. This results in formation of high-alloy carbides beneath the steel surface, and a complete disappearance of the alloy ferrite matrix to a depth exceeding $50 \mu \mathrm{m}$. On the other hand, the carbide particles beneath the surface of $2.25 \mathrm{Cr}-1 \mathrm{Mo}$ steel grow in size and become impoverished in the alloy elements. Just at the surface, the carbides are so closely distributed that they form not uniform layer of maximum thickness $2 \mu \mathrm{m}$. 
The morphology of carbides decides on further corrosion progression. The carbides at the steel surface may constitute a barrier for the inward transport of carbon that results in deposition of carbon on the steel surface and a start of dust formation. The subsurface carbide layer in $2.25 \mathrm{Cr}-1 \mathrm{Mo}$ steel can be easily interrupted during high-temperature service of the tube that allows for continuous carbon transport up to the middle-wall [14]. On the other hand, the thick carbide layer beneath $9 \mathrm{Cr}-1 \mathrm{Mo}$ steel surface is an effective barrier for the inward transport of carbon causing disintegration of the layer into dust composed of carbides, metal particles and graphite [13]. It should be noted, however, that some other destructive techniques, non-destructive examinations, inspection and operation history are needed to determine the detailed mechanism of the corrosion.

\section{CONCLUSIONS}

From destructive examinations of $2.25 \mathrm{Cr}-1 \mathrm{Mo}$ and $9 \mathrm{Cr}-1 \mathrm{Mo}$ steel tubes at advanced stages of metal dusting process after long-term service in catalytic reforming charge heaters it may be concluded that the SEM/EDS technique provide enough information for the evaluation of probable mechanisms of metal dusting corrosion and can be helpful in an assessment of immediate fitness for the purpose and long-term service capability of the components during and following shutdowns:

- In $2.25 \mathrm{Cr}-1 \mathrm{Mo}$ steel tube, disintegration of the subsurface carbides into a dust is limited and carburization up to the middle-wall tends to be prevalent. High risk of failure may be expected because deep carburization leads to crack initiation and through-wall propagation of the cracks.

- In 9Cr-1Mo steel tube, over-saturation of the subsurface material results in formation of a thick carbide layer that effectively blocks further carbon ingress. Disintegration of the layer into dust may favour an increase of dust in the installation, and cause erosion of tube headers in charge heaters, and pollution of catalyst in reactors during future service. No risk of tube failure exists if the corrosion progress is slow and uniform.

\section{REFERENCES}

1. Hochman R.F.: Catastrophic Deterioration of high temperature alloys in carbonaceous atmospheres, in: Proceedings of the Symposium on Properties of High Temperature Alloys with Emphasis on Environmental Effects. Z.A. Foroulis and F.S. Pettit [ed.], The Electrochemical Society, Pennington NY 1977, pp. 715732.

2. Lai G.Y.: High-temperature corrosion of engineering alloys. ASM International, Materials Park, Ohio, 1997. 
3. Grabke H.J.: Metal dusting, in: Corrosion by carbon and nitrogen. Metal dusting, carburisation and nitridation. H.J. Grabke and M. Schütze [ed.], Woodhead Publishing Limited, Cambridge, England, 2007, pp. 1-24.

4. Grabke H.J.: Thermodynamics, mechanisms and kinetics of metal dusting. Materials and Corrosion 49 (1998), pp. 303-308.

5. Grabke H.J.: Mechanisms of metal dusting of low and high alloy steels. Solid State Phenomena 41 (1995), pp. 3-16.

6. Grabke H.J., Bracho-Troconis C.B, Müller-Lorenz E.M.: Metal dusting of low alloy steels. Materials and Corrosion 45 (1994), pp. 215-221.

7. Straub S., Grabke H.J.: Role of alloying elements in steels on metal dusting. Materials and Corrosion 49 (1998), pp. 321-327.

8. Grabke H.J.: Metal dusting of low- and high-alloy steels. Corrosion 9, (1995) pp. 711-720.

9. Pippel E., Woltersdorf J., Schneider R.: Micromechanisms of metal dusting on Febase and Ni-base alloys. Materials and Corrosion 49 (1998) pp. 309-316.

10. Pippel E., Woltersdorf J., Grabke H.J., Strauß S.: Microprocesses of metal dusting on iron. Steel Research 66 (1995) pp. 217-221.

11. Chun C.M., Ramanarayanan T.A.: Metal-Dusting Corrosion of Low-Chromium Steels. Oxidation of Metals 62 (2004) pp. 71-92.

12. Chun C. M., Mumford J.D., Ramanarayanan T.A.: Relationship between coking and metal dusting. Materials and Corrosion 50 (1999) pp. 634-639.

13. Dampc J., Grzesik Z., Hucińska J.: Metal dusting in CCR platforming unit. Materials and Corrosion 60 (2009), pp. 211-217.

14. Hucińska J., Gajowiec G., Derewnicka D.: Mechanism of carburisation and metal dusting of 2.25Cr-1Mo steel in catalytic reforming unit. [W] Proc. EUROCORR 2009, European Federation of Corrosion. Nice, France 2009. 